\title{
Improving patient outcomes following total joint arthroplasty: is there an app for that?
}

\author{
Jesse I Wolfstadt, ${ }^{1,2}$ Christine Soong, ${ }^{3}$ Sarah E Ward ${ }^{2,4}$
}

${ }^{1}$ Granovsky Gluskin Division of Orthopaedics, Mount Sinai Hospital, Toronto, Ontario, Canada

${ }^{2}$ Department of Surgery, University of Toronto Faculty of Medicine, Toronto, Ontario, Canada

${ }^{3}$ GIM, Mount Sinai Hospital, Toronto, Ontario, Canada ${ }^{4}$ Department of Orthopaedic Surgery, St. Michael's Hospital, Toronto, Ontario, Canada

\section{Correspondence to}

Dr Jesse I Wolfstadt,

Orthopaedics, Mount Sinai Hospital, Toronto, ON M5G 1X5, Canada;

Jesse.Wolfstadt@ sinaihealthsystem.ca

Accepted 2 May 2019 Published Online First 20 May 2019

\section{Linked}

- http://dx.doi.org/10.1136/ bmjqs-2018-008975

\section{Check for updates}

(c) Author(s) (or their employer(s)) 2019. No commercial re-use. See rights and permissions. Published by BMJ.

To cite: Wolfstadt JI, Soong C, Ward SE. BMJ Qual Saf 2019;28:775-777.
Patient activation, defined as an individual's knowledge, skill and confidence in managing their health and healthcare, is recognised as a critical aspect of highquality, patient-centred and safe healthcare. $^{1}$ In 2004, Judith Hibbard and colleagues published their seminal work on the development of a validated, objective measure of patient activation. ${ }^{1}$ The Patient Activation Measure (PAM) was designed to assess patient self-reported knowledge, skills and confidence for managing one's health or chronic illness. The original 22-item PAM was subsequently shortened to a 13-item version and was found to be both reliable and valid for assessing patient activation. ${ }^{2}$ Patient activation has the potential to reduce healthcare costs, optimise healthcare utilisation, enhance population health by encouraging healthy behaviours and improve patient outcomes and satisfaction. ${ }^{3-5}$

Total knee arthroplasty (TKA) represents an important opportunity to study the effectiveness of patient activation. Historically, up to $15 \%-20 \%$ of patients remain dissatisfied following a total joint arthroplasty (TJA). ${ }^{67}$ This is especially true of patients undergoing TKA and remains a troublesome challenge for orthopaedic surgeons and their patients. ${ }^{8}$ To date, it remains unclear why some patients remain unsatisfied with their knee function following TKA, despite having technically successful surgeries when examined from the surgeon's perspective. Previous attempts to address the subgroup of dissatisfied patients undergoing TKA through modifications to implant design and alterations in surgical technique have generally failed. Focus then shifted to patient characteristics, with some evidence that patient factors such as mental health scores and patient expectations are predictive of postoperative patient satisfaction..$^{9-12}$ It stands to reason that interventions designed to improve patient activation may modify the risk of poor patient experience.

While promising, the literature investigating patient activation in orthopaedics is scarce and represents opportunity for scientific evaluation. ${ }^{13}{ }^{14}$ Identifying patients with low patient activation may allow orthopaedic surgeons to predict patients at risk of poor outcomes and develop mitigation strategies. Activated patients may have more realistic expectations following surgery, and therefore better patient-centred outcomes such as satisfaction, pain scores and knee function. $^{15} 16$ Furthermore, greater patient activation may lead to improvements in coping and self-care strategies used by patients as they navigate the recovery process. The early postoperative period following TKA can be challenging, as patients must cope with significant pain and swelling while also actively engaging in an aggressive physiotherapy programme in order to ensure a positive long-term functional outcome. Better patient activation and coping skills during this phase of recovery can be a useful strategy.

The use of technology such as an interactive multimedia intervention is appealing due to ease of application and feasibility in busy settings such as outpatient clinics or fast-paced inpatient wards. A common concern for patients undergoing TKA is the fear of being unable to cope with pain once they return home. ${ }^{17}$ It has been shown that higher preoperative patient activation scores correlate with better postoperative patient-reported outcomes in patients undergoing TJA, including pain scores. ${ }^{13}$ However, it is not yet entirely clear how and to what extent patient activation can be modified. 
In this issue of BMJ Quality and Safety, McDonall et al describe the impact of a bedside multimedia intervention for patients undergoing TKA. ${ }^{18}$ The authors report better pain scores, length of stay, knee function and satisfaction with care for patients exposed to the intervention (a multimedia presentation using text, sound, graphics and animations to provide information tailored to each day of recovery) through a portable tablet device. Interestingly, the study showed that PAM scores actually decreased during the inpatient stay, although to a lesser degree in those patients who were exposed to the intervention, returning to baseline levels by 4 weeks postdischarge. This raises new questions regarding the impact of interventions limited to the inpatient setting on patient activation. The utility of tools such as web-based platforms and mobile apps to improve patient activation remains unclear, particularly in the inpatient setting. ${ }^{19}$ Furthermore, while additional supports provided during the inpatient stay may provide marginal improvements in patient experience and/or activation, the true challenge for improving postsurgical recovery lies in the immediate postdischarge period. ${ }^{20}$ It is in the early days after hospital discharge that surgical patients feel most adrift, not knowing what to expect as part of the 'normal' recovery. Many wonder if pain, swelling and other symptoms experienced represent part of the usual recovery process or herald the onset of a worrying complication.

If technological interventions are able to improve the transition from inpatient to outpatient care following surgery, they can enhance patient experience and activation and even impact healthcare utilisation. Campbell et al recently demonstrated that automated text messages sent to patients undergoing TJA can improve time spent on home exercises, enhance patients' mood, decrease narcotics use and minimise calls to the surgeon's office. ${ }^{21}$ Additionally, patient activation may reduce unnecessary emergency department visits and decrease morbidity through early and accurate identification of postoperative complications. With the increasing and now ubiquitous use of smartphones and tablet computers in the general population for fitness, meditation and other lifestyle improvements, these platforms provide an excellent opportunity for physicians to engage with patients. Harnessing such technologies has been shown to be beneficial for both patients and providers in the postsurgical period by reducing the need for inpatient follow-up visits while also being cost-effective. ${ }^{22}$ Mobile apps have demonstrated impact in chronic disease management by improving patient activation and blood pressure and glycaemic control. ${ }^{2324}$ Interestingly, negative mobile app studies seem to suggest that when technologies are used as a passive educational intervention, patient activation may suffer. ${ }^{25} 26$

One possible key ingredient to successful patient activation is the engagement of the healthcare team that is facilitated through mobile technology. Where these technologies were used as tools to facilitate greater communication and interaction, patient activation has been shown to be increased and outcomes improved. ${ }^{232427}$ In the way that surgical checklists are believed to be necessary but not sufficient to reduce adverse events, ${ }^{28}$ technological interventions may be effective only if implemented in a manner that improves a patient's connexion with the healthcare team. Technology alone, such as an app that can only be accessed during a hospital stay, is unlikely to result in sustained increases in patient activation as patients will present with different needs during subsequent stages of recovery (eg, post-discharge). Through a qualitative study of user needs related to TKA, van Kasteren et al showed that information and communication needs indeed change throughout the TKA 'journey', concluding that opportunities to leverage technological solutions are therefore dependent on both the patient's stage of recovery as well as the specific goal of the intervention. ${ }^{29}$ Indeed, the need for clinicians to deliver the 'right information at the right time' was a key finding of the study by van Kasteren et al, which also concluded that digital technology could facilitate improved communication from patients to clinicians. ${ }^{29}$ In summary, users of technology to promote patient activation must recognise the need to actively integrate patients into the healthcare team as well as to inspire them to take control of their own care.

Mobile apps and other technological interventions also must have clear goals if they are to be used successfully; and these goals are likely to differ for different patient populations and disease processes. As the study by van Kasteren et al showed, interventions that are found to be successful for inpatients may be quite different from those that have utility for patients who are either preparing for or recovering from surgery at home. ${ }^{29}$ Additional research is needed to determine the key interventions required to successfully increase patient activation at each stage in a patient's journey, beginning with the decision to undergo surgery and ending once maximal recovery has been achieved. Educational interventions may be more important prior to surgery while daily reminders, symptom tracking and automated triggers resulting in contact with a member of the care team may be most helpful in the early postoperative period. In addition to tailoring the type of intervention, personalisation has also been shown to be a key feature of the so-called 'persuasive eCoaching' interventions (ie, interventions designed to motivate groups of people to alter their behaviours and attitudes). ${ }^{30}$ Personalising the timing, content and type of digital technology intervention depending on patient factors may therefore lead to greater improvements in outcomes such as patient activation and self-efficacy following TKA. Improving patient activation clearly holds promise for improving outcomes related to modifiable patient factors, and harnessing 
mobile technologies to achieve this goal may be the path forward. The key to success will likely be tailoring interventions to meet the specific needs of individual patients at different stages in the TKA journey.

Funding The authors have not declared a specific grant for this research from any funding agency in the public, commercial or not-for-profit sectors.

Competing interests None declared.

Patient consent for publication Not required.

Provenance and peer review Commissioned; internally peer reviewed.

\section{REFERENCES}

1 Hibbard JH, Stockard J, Mahoney ER, et al. Development of the patient activation measure (PAM): Conceptualizing and measuring activation in patients and consumers. Health Serv Res 2004;39:1005-26.

2 Hibbard JH, Mahoney ER, Stockard J, et al. Development and testing of a short form of the patient activation measure. Health Serv Res 2005;40:1918-30.

3 Hibbard JH, Greene J, Overton V. Patients With Lower Activation Associated With Higher Costs; Delivery Systems Should Know Their Patients' 'Scores'. Health Affairs 2013;32:216-22.

4 Tzeng A, Tzeng TH, Vasdev S, et al. The role of patient activation in achieving better outcomes and cost-effectiveness in patient care. JBJS Rev 2015;3.

5 Barker I, Steventon A, Williamson R, et al. Self-management capability in patients with long-term conditions is associated with reduced healthcare utilisation across a whole health economy: cross-sectional analysis of electronic health records. BMJ Qual Saf 2018;27:989-99.

6 Bourne RB, Chesworth BM, Davis AM, et al. Patient satisfaction after total knee arthroplasty: who is satisfied and who is not? Clin Orthop Relat Res 2010;468:57-63.

7 Anakwe RE, Jenkins PJ, Moran M. Predicting dissatisfaction after total hip arthroplasty: a study of 850 patients. $J$ Arthroplasty 2011;26:209-13.

8 Dunbar MJ, Richardson G. I can't get no satisfaction after my total knee replacement: rhymes and reasons. Bone Joint J 2013;95-B(11 Suppl A):148-52.

9 Dowsey MM, Spelman T, Choong PFM. Development of a prognostic nomogram for predicting the probability of nonresponse to total knee arthroplasty 1 year after surgery. $J$ Arthroplasty 2016;31:1654-60.

10 Gandhi R, Davey JR, Mahomed NN. Predicting patient dissatisfaction following joint replacement surgery. $J$ Rheumatol 2008;35:2415-8.

11 Neuprez A, Delcour J-P, Fatemi F, et al. Patients' Expectations Impact Their Satisfaction following Total Hip or Knee Arthroplasty. Plos One 2016;11:e0167911.

12 Tilbury C, Haanstra TM, Leichtenberg CS, et al. Unfulfilled expectations after total hip and knee arthroplasty surgery: there is a need for better preoperative patient information and education. J Arthroplasty 2016;31:2139-45.

13 Andrawis J, Akhavan S, Chan V, et al. Higher preoperative patient activation associated with better patient-reported outcomes after total joint arthroplasty. Clin Orthop Relat Res 2015;473:2688-97.
14 Skolasky RL, Mackenzie EJ, Wegener ST, et al. Patient activation and functional recovery in persons undergoing spine surgery. J Bone Joint Surg Am 2011;93:1665-71.

15 Filbay SR, Judge A, Delmestri A, et al. Evaluating patients' expectations from a novel patient-centered perspective predicts knee arthroplasty outcome. J Arthroplasty 2018;33:2146-52.

16 Hoorntje A, Leichtenberg CS, Koenraadt KLM, et al. Not physical activity, but patient beliefs and expectations are associated with return to work after total knee arthroplasty. $J$ Arthroplasty 2018;33:1094-100.

17 Darlow B, Brown M, Thompson B, et al. Living with osteoarthritis is a balancing act: an exploration of patients' beliefs about knee pain. BMC Rheumatol 2018;2.

18 McDonall J, de Steiger R, Reynolds J, et al. Patient activation intervention to facilitate participation in recovery after total knee replacement (mime): a cluster randomised cross-over trial. BMJ Qual Saf 2019;28:782-92.

19 Prey JE, Woollen J, Wilcox L, et al. Patient engagement in the inpatient setting: a systematic review. J Am Med Inform Assoc 2014;21:742-50.

20 Specht K, Agerskov H, Kjaersgaard-Andersen P, et al. Patients' experiences during the first 12 weeks after discharge in fasttrack hip and knee arthroplasty - a qualitative study. Int J Orthop Trauma Nurs 2018;31:13-19.

21 Campbell KJ, Louie PK, Bohl DD, et al. A novel, automated Text-Messaging system is effective in patients undergoing total joint arthroplasty. J Bone Joint Surg Am 2019;101:145-51.

22 Armstrong KA, Semple JL, Coyte PC. Replacing ambulatory surgical follow-up visits with mobile app home monitoring: modeling cost-effective scenarios. J Med Internet Res 2014;16:e213.

23 Milani RV, Lavie CJ, Bober RM, et al. Improving Hypertension control and patient engagement using digital tools. Am J Med 2017;130:14-20.

24 Su D, Michaud TL, Estabrooks P, et al. Diabetes management through remote patient monitoring: the importance of patient activation and engagement with the technology. Telemedicine and e-Health 2018.

25 Ledford CJW, Womack JJ, Rider HA, et al. Unexpected effects of a System-Distributed mobile application in maternity care: a randomized controlled trial. Health Educ Behav 2018;45:323-30.

26 Plate JF, Ryan SP, Bergen MA, et al. Utilization of an electronic patient portal following total joint arthroplasty does not decrease readmissions. J Arthroplasty 2018.

27 Titova E, Salvesen Øyvind, Bentsen SB, et al. Does an integrated care intervention for COPD patients have long-term effects on quality of life and patient activation? A prospective, open, controlled single-center intervention study. Plos One 2017;12:e0167887.

28 Gagliardi AR, Straus SE, Shojania KG, et al. Multiple interacting factors influence adherence, and outcomes associated with surgical safety checklists: a qualitative study. PLoS ONE 2014;9:e108585.

29 van Kasteren Y, Freyne J, Hussain MS. Total knee replacement and the effect of technology on Cocreation for improved outcomes and delivery: qualitative Multi-Stakeholder study. $J$ Med Internet Res 2018;20:e95.

30 Lentferink AJ, Oldenhuis HKE, de Groot M, et al. Key components in eHealth interventions combining Self-Tracking and persuasive eCoaching to promote a healthier lifestyle: a scoping review. J Med Internet Res 2017;19:e277. 